\title{
Cardiac Findings in Amyotrophic Lateral Sclerosis: A Magnetic Resonance Imaging Study
}

\author{
Angela Rosenbohm ${ }^{1 *}$, Benjamin Schmid ${ }^{1,2}$, Dominik Buckert ${ }^{3}$, Wolfgang Rottbauer ${ }^{3}$, \\ Jan Kassubek ${ }^{1}$, Albert C. Ludolph ${ }^{1}$ and Peter Bernhardt ${ }^{4}$
}

${ }^{1}$ Department of Neurology, University of Ulm, Ulm, Germany, ${ }^{2}$ Department of Internal Medicine, Kreiskrankenhaus Ehingen, Ehingen, Germany, ${ }^{3}$ Department of Internal Medicine II, University of Ulm, Ulm, Germany, ${ }^{4}$ Heart Clinic UIm, Ulm, Germany

The objective of this study was to investigate the potential involvement of cardiac structure and function by cardiac magnetic resonance (CMR) imaging in amyotrophic lateral sclerosis (ALS) patients. Our study included 35 patients with ALS without a history of cardiac disease and an age- and gender-matched healthy control group $(n=34)$. All subjects received a CMR in a 1.5-T whole-body scanner. Patients were also screened with Holter

OPEN ACCESS

Edited by:

Ghazala Hayat,

Saint Louis University,

United States

Reviewed by:

Janice C. Wong,

Brigham and Women's Hospital, United States

Holli A. Horak,

University of Arizona,

United States

*Correspondence:

Angela Rosenbohm

angela.rosenbohm@uni-ulm.de

Specialty section:

This article was submitted to

Neuromuscular Diseases,

a section of the journal

Frontiers in Neurology

Received: 27 June 2017

Accepted: 29 August 2017

Published: 27 September 2017

Citation:

Rosenbohm A, Schmid B, Buckert D,

Rottbauer W, Kassubek J,

Ludolph AC and Bernhardt P (2017)

Cardiac Findings in Amyotrophic

Lateral Sclerosis: A Magnetic

Resonance Imaging Study.

Front. Neurol. 8:479.

doi: 10.3389/fneur.2017.00479 monitoring, echocardiography, and a blood test of cardiac markers. Myocardial mass in ALS hearts was reduced compared to the control group, and ejection volumes in the left and right heart were severely decreased in ALS patients, as shown by echocardiography and CMR. The myocardium showed increased T1 enhancement in $77 \%$ of the patients compared to $27 \%$ of controls ( $p=0.0001$ ). A trend toward late gadolinium enhancement patterns consistent with myocardial fibrosis was observed in $23.5 \%$ of the patients $(9.1 \%$ of controls). Holter monitoring was normal in all patients as well as troponin T. Cardiac involvement seems to be present in ALS patients without clinical cardiac symptoms and with a normal cardiac routine assessment. Structural myocardial defects in CMR may be due to sympathetic dysfunction and may account for reported cardiac deaths in late-stage ALS patients.

Keywords: amyotrophic lateral sclerosis, cardiac magnetic resonance tomography, cardiac involvement, sympathetic dysfunction, heart

\section{INTRODUCTION}

A common limiting factor for life expectancy of amyotrophic lateral sclerosis (ALS) patients is respiratory failure that is caused by paresis of respiratory muscles as well as aspiration and resulting pneumonia $(1,2)$. Another common cause of death in ALS is sudden cardiac death $(1,3)$. In recent years, several studies have shown that the autonomic nervous system is also involved in ALS, since increased heart rate variability (4) and increased QTc intervals in electrocardiogram (ECG) have been reported (5). Decreased heart rate variability and a loss of correlation between blood pressure and heart rate also have been described $(6,7)$. Cardiac involvement has been reported in ALS by ECG, echocardiography (8), and postmortem examination (5). The involvement of the autonomic nervous system could increase the risk of heart rhythm disturbances or sudden cardiac death $(9,10)$. Subclinical cardiac involvement has been reported $(11,12)$, including non-specific ECG and echocardiographic abnormalities. In summary, cardiac involvement in ALS seems to be frequent, but systematic information on functional and structural deficits does not seem to be present. 
Cardiac magnetic resonance (CMR) imaging is a valuable tool in the diagnostic assessment of inflammatory myocarditis (13-16) and for the detection of cardiac involvement in systemic muscle diseases $(17,18)$. The aim of this study was to characterize cardiac involvement in ALS using a comprehensive CMR protocol.

\section{MATERIALS AND METHODS}

\section{Patients and Controls}

All patients included had possible, probable, or definite ALS according to the revised El Escorial criteria. Patients participating in the diagnostic assessment at the Department of Neurology, University of Ulm (Germany) and in the regional ALS registry (ALS Register Swabia REF) were prospectively screened and enrolled in the study. In total, 53 patients were screened and provided written informed consent. Eighteen of these patients had to be excluded due to claustrophobia or inability to lie supine because of respiratory dysfunction. The ALS Register Swabia and this CMR study were approved by the local Ethics Committee of the University of Ulm (protocols no. $11 / 10$ and no. $05 / 11$ ).

Exclusion criteria were contraindications for CMR or gadolinium-based contrast agent or pregnancy.

Blood levels of troponin T, creatine kinase (CK), myocardial creatine kinase (CK-MB), and $N$-terminal pro brain natriuretic peptide (NT-pro BNP) were analyzed in each patient. For NTpro BNP, normative age-related values were used (19).

As controls, a cohort of age and gender matched patients was implemented. These patients exhibited no signs of cardiac insufficiency. Clinical characteristics of ALS patients and controls are presented in Table $\mathbf{1}$.

\section{Holter Monitoring}

A 24-h Holter monitoring was performed using a Digi Trac XT recorder (Philips Healthcare). Holter monitoring was considered abnormal in the presence of; atrioventricular block grade I-III, atrial fibrillation/flutter (AF/AFL), other supraventricular tachyarrhythmia (SVT) [>30 supraventricular premature contractions (SVPC) per hour or runs of $\geq 20$ SVPC], frequent ventricular premature contractions (VPCs) $(\geq 30 / \mathrm{h})$, and nonsustained ventricular tachycardy (NSVT).

\section{Transthoracic Echocardiography}

Transthoracic echocardiography was performed using a CX 50 Ultrasound (Philips Healthcare Germany). Left ventricular (LV) cavity dimensions, mass and wall thickness and diastolic dysfunction were assessed in accordance with the recommendations of the European Association of Echocardiography (20).

An abnormal echocardiography was defined by the following diameters of the left ventricle: a left ventricular end-diastolic diameter (LVEDD) $>56 \mathrm{~mm}$, an interventricular septum (IVS) $>11 \mathrm{~mm}$ and a left ventricular end systolic diameter (LVESD) $>40 \mathrm{~mm}$. The ejection fraction was visually evaluated. In addition, echocardiography was used to assess valve disease and fractional shortening (FS).
TABLE 1 | Clinical characteristics of amyotrophic lateral sclerosis (ALS) patients and controls.

\begin{tabular}{|c|c|c|}
\hline & $\begin{array}{l}\text { ALS patients } \\
(N=35)\end{array}$ & $\begin{array}{l}\text { Controls } \\
(N=34)\end{array}$ \\
\hline Age $(y)$, mean $\pm S D$ & $69.54 \pm 10.64$ & $68.06 \pm 9.59$ \\
\hline Females, $n(\%)$ & $18(51.4)$ & $18(52.9)$ \\
\hline Arterial hypertension, $n(\%)$ & $16(45.7)$ & $11(32.4)$ \\
\hline Diabetes, $n(\%)$ & $7(20)$ & $1(3)$ \\
\hline Body mass index mean $\pm \mathrm{SD}\left(\mathrm{kg} / \mathrm{m}^{2}\right)$ & $25.0 \pm 5.3$ & $25.8 \pm 4.2$ \\
\hline ALS functional rating scale, points & $32.4 \pm 8.5$ & - \\
\hline Forced vital capacity, \% & $66.11 \pm 25.30$ & - \\
\hline Spinal/bulbar, $n$ & 23/12 & - \\
\hline Creatine kinase (norm <171), U/I & $244 \pm 266$ & - \\
\hline Myocardial creatine kinase (norm <25), U/l & $24 \pm 14$ & - \\
\hline Troponin T (norm <14), ng/l & $0 \pm 0$ & - \\
\hline $\begin{array}{l}\text { N-terminal pro brain natriuretic peptide } \\
\text { (norm 0-125), pg/ml }\end{array}$ & $149 \pm 206$ & - \\
\hline $\begin{array}{l}\text { Angiotensin converting enzyme inhibitor } \\
\text { and angiotensin } 1 \text { receptor blockers, } n\end{array}$ & $10 / 35$ & - \\
\hline Beta-blocker, $n$ & $8 / 35$ & - \\
\hline Other antihypertensive medication, $n$ & $4 / 35$ & - \\
\hline AVB grade $I, n$ & 0 & - \\
\hline Atrial fibrillation, $n$ & 0 & - \\
\hline Supraventricular tachycardia, $n$ & 0 & - \\
\hline NSVT, $n$ & 0 & - \\
\hline VCP/h (0-100), $n$ & $20 / 26$ & - \\
\hline
\end{tabular}

NSVT, non-sustained ventricular tachycardia; AVB, atrioventricular block; VPC/h, ventricular premature contractions/hour.

\section{CMR Study}

All patients were examined in a 1.5 - $\mathrm{T}$ whole-body scanner (Intera, Philips Medical Systems, Best, The Netherlands) using a 32-channel phased-array cardiac surface coil. Steady-state free precession cine sequences were acquired in a contiguous short axis orientation covering the LV and right ventricle for volumetric and functional analysis of both ventricles (repetition time $3.4 \mathrm{~ms}$, echo time $1.7 \mathrm{~ms}$, slice thickness $8 \mathrm{~mm}$, no interslice gap, and acquisition in end-expiration breath-hold) as previously reported (20).

Ten minutes after an intravenous application of $0.2 \mathrm{mmol} / \mathrm{kg}$ body-weight gadolinium-based contrast agent (Dotarem, Guerbet, Villepinte, France), an inversion-recovery gradientecho sequence for evaluation of late gadolinium enhancement (LGE) was acquired in a contiguous short axis orientation covering the entire left ventricle (repetition time $7.1 \mathrm{~ms}$, echo time $3.2 \mathrm{~ms}$, slice thickness $8 \mathrm{~mm}$, respiratory navigator, and inversion time was individually adjusted for complete nulling of the myocardium) (21).

\section{CMR Analysis}

Cardiac magnetic resonance images (DICOM) were anonymized and transferred to a workstation. Two blinded and experienced readers $(\mathrm{DB}, \mathrm{PB})$ evaluated all images in consensus using commercially available software (cmr42, Circle, Cardiovascular Imaging, Calgary, AB, Canada). End-diastolic and end-systolic endocardial contours of the LV and right ventricle were drawn manually for evaluation of end-diastolic and end-systolic volumes, and the ejection fractions were calculated. In addition, end-diastolic LV epicardial contours were drawn for the assessment of LV myocardial mass. 
For an early gadolinium enhancement compared to a thoracic skeletal muscle, early gadolinium enhancement ratio (EGEr) (14) or T1 ratio/heart/skeletal muscle (22) were chosen for analysis. In the event of gadolinium enhancement $>20 \%$ in thoracic skeletal muscle, instead of analyzing a ratio an absolute value of $>45 \%$ was used as cut-off for myocardial enhancement (23). For a $\mathrm{T} 1$ ratio, values $>4$ were considered to be increased. These criteria are well established and suggested for CMR diagnostic assessment of inflammatory myocardial disease (14). Increased myocardial T1 enhancement consists of either a pathological T1 ratio or an EGEr $>45 \%$.

The inversion-recovery gradient-echo sequence was evaluated for the presence of a hyper-enhancement consistent with myocardial fibrosis. LGE volume was quantified as a percentage of the LV myocardial mass using a cutoff signal intensity increase of more than five SDs of remote myocardium (21). An LGE pattern was globally assessed as ischemic with a subendocardial and/or transmural enhancement and non-ischemic with subepicardial and/or intramural enhancement.

\section{Statistical Analysis}

All data are reported as a mean value \pm SD in comparison to the control group. An unpaired $t$-test was used for the cohort comparison. A $p$-value $\leq 0.05$ was regarded as statistically significant.

\section{RESULTS}

Twelve patients had bulbar onset and spinal onset was seen in 23 cases. Mean disease duration at CMR was $2.6 \pm 2.2$ years and mean ALS functional rating scale (ALSFRS)-R score was $32.4 \pm 8.5$ points. None of the patients had any cardiac complaints. Patients were characterized with respect to cardiovascular risk factors, antihypertensive co-medication, and vital capacity as indicated in Table 1. Holter monitoring was performed on 26 patients and did not show any abnormalities. Healthy controls were clinically characterized for arterial hypertension (AHT) and diabetes.

\section{Holter Monitoring}

In particular, we did not find any abnormality on Holter monitoring in patients with ALS $(n=26)$, with regard to atrial fibrillation/flutter, supraventricular tachycardia, atrioventricular block, and non-sustained ventricular tachycardia.

Several premature ventricular contractions were monitored (Table 1). Overall, no association was observed between abnormal myocardial CMR (T1 Ratio, LGE) and abnormal findings on Holter monitoring.

\section{Echocardiography}

Echocardiography revealed normal diameters of the ventricles. The systolic function was not diminished in the visual evaluation with normal values of FS. Slight insufficiencies of the aortic, tricuspidal and mitral valve were reported in several patients. All other documented values were in the normal range (Table 2). No pericardial effusions were reported.
TABLE 2 | Results of echocardiography in 30 amyotrophic lateral sclerosis (ALS) patients.

\begin{tabular}{lc}
\hline & ALS patients \\
\hline LA (norm <40), mean \pm SD (mm) & $37.7 \pm 6.4$ \\
LVEDD (norm <56 mm), mean \pm SD (mm) & $46.2 \pm 4.6$ \\
LVESD (norm <42 mm), mean \pm SD (mm) & $26.2 \pm 4.0$ \\
FS fractional shortening (LVEDD-LVESD) & $40.4 \pm 6.6$ \\
(norm > 25\%), mean \pm SD (\%) & \\
IVSDD (norm 5-11 mm), mean \pm SD (mm) & $9.6 \pm 2.0$ \\
Al (slight), $n$ & $7 / 30$ \\
MI (slight), $n$ & $13 / 30$ \\
TI (slight), $n$ & $15 / 30$ \\
\hline
\end{tabular}

$L A$, left atrium; $L V E D D$, left ventricular end-diastolic diameter; LVESD, left ventricular end systolic diameter; FS, fractional shortening; IVSDD, intraventricular septum end-diastolic diameter; Al, aortic insufficiency; MI, mitral insufficiency; TI, tricuspidal insufficiency.

\section{Blood Tests}

Creatine kinase was elevated in 14/35 patients (mean $239 \pm 265 \mathrm{U} / \mathrm{l}$, normal range $<171 \mathrm{U} / \mathrm{l}$ ) and CK-MB in 6/22 (mean $24 \pm 14 \mathrm{U} / \mathrm{l}$, normal range $<25 \mathrm{U} / \mathrm{l})$. Troponin $\mathrm{T}$ was normal in all patients tested $(N=28)$. NT-pro BNP (with age- and gender-correlated normative values) was abnormal in $3 / 35$ patients, indicating myocardial insufficiency. One of these patients showed a previous myocardial ischemia and the other two showed pericardial effusions.

\section{CMR Data}

Cardiac magnetic resonance was completed in 35 ALS patients and 34 controls. Mean left and right ventricular ejection fractions (LVEF and RVEF) were in the normal range (Table 3), but myocardial mass and myocardial volumes were significantly reduced in ALS patients compared to the control group (LV stroke volume, left ventricular end-diastolic volume (LVEDV), ventricular mass, right ventricular stroke volume, and right ventricular end-diastolic volume). $N=27$ ALS hearts had LVEF $>60 \%$ of which $n=18$ had increased T1 enhancement (67\%) compared to $N=22$ normal control hearts of which 6 had increased $\mathrm{T} 1$ enhancement (27\%).

Reduced LV function (ejection fraction $<60 \%$ ) was observed in $6 / 33$, and five of these patients also showed increased T1 enhancement. $N=12$ controls had reduced LVEF, 2 of them had increased $\mathrm{T} 1$ ratio.

The mean LVEF in ALS patients was 64\% (range 52-80) compared to controls (mean 60\%, range $27-85$ ). Early myocardial gadolinium enhancement in T1 could be observed in 24/31 $(77 \%)$ of ALS patients (Figure 1) and in 8/30 controls, which was statistically different $(p=0.0001)$.

$8 / 35$ patients had a pericardial effusion without a hemodynamic restriction (Figure 2) which was also detected in $6 / 34$ controls. There was no significant difference from healthy controls. The detected pericardial effusions in the CMR were not visible in the echocardiography.

Late gadolinium enhancement patterns consistent with a myocardial fibrosis were detected in eight $(23 \%)$ patients, but this abnormality did not reach significance, since three controls also had a pathological LGE. In four ALS patients, LGE was distributed in the basal inferolateral segments (Figure 3). In one 
TABLE 3 | Cardiac magnetic resonance (CMR) characteristics of 35 ALS cases.

\begin{tabular}{|c|c|c|c|c|}
\hline & Unit & ALS cohort $n=35$ & Control cohort $n=34$ & Unpaired $t$-test $p$-value \\
\hline Age (years) & Mean \pm SD & $69.54 \pm 10.64$ & $68.06 \pm 9.59$ & 0.55 \\
\hline Females, $n(\%)$ & Frequency & $18(51.4)$ & $18(52.9)$ & 0.90 \\
\hline $\mathrm{AHT}, n(\%)$ & Frequency & $16(45.7)$ & $11(32.4)$ & 0.26 \\
\hline Diabetes, $n(\%)$ & Frequency & $7(20)$ & $1(3)$ & 0.03 \\
\hline LVEDV (ml) & Median $(5 ; 95)$ & $99(68 ; 158.2)$ & $136(82.4 ; 213.6)$ & 0.0001 \\
\hline LVEDV index $\left(\mathrm{ml} / \mathrm{m}^{2}\right)$ & Median $(5 ; 95)$ & 57.74 (29.09; 88.14) & $73.18(42.78 ; 110.6)$ & $<0.0001$ \\
\hline LVSV (ml) & Mean \pm SD & $68.30 \pm 17.62$ & $82.09 \pm 20.66$ & 0.0046 \\
\hline LVSV index $\left(\mathrm{ml} / \mathrm{m}^{2}\right)$ & Mean \pm SD & $37.05 \pm 9.737$ & $44.75 \pm 10.34$ & 0.0024 \\
\hline Ventricular mass (g) & Mean \pm SD & $79.38 \pm 26.16$ & $99.0 \pm 27.30$ & 0.0047 \\
\hline Ventricular mass index $\left(\mathrm{g} / \mathrm{m}^{2}\right)$ & Mean \pm SD & $41.98 \pm 16.04$ & $50.3 \pm 17.36$ & 0.0435 \\
\hline LVEF (\%) & Median $(5 ; 95)$ & $64(55.2 ; 74.7)$ & $62(44.4 ; 75.6)$ & 0.034 \\
\hline RVEDV (ml) & Median $(5 ; 95)$ & $96(67 ; 163.65)$ & $134(68.6 ; 219.2)$ & 0.0005 \\
\hline RVEDV index (ml/m²) & Median $(5 ; 95)$ & $55.63(27.35 ; 88.23)$ & 77.63 (35.82; 115.7) & $<0.0001$ \\
\hline RVSV (ml) & Mean \pm SD & $65.16 \pm 18.59$ & $82.59 \pm 21.87$ & 0.001 \\
\hline RVSV index $\left(\mathrm{ml} / \mathrm{m}^{2}\right)$ & Mean $\pm S D$ & $35.53 \pm 10.24$ & $45.00 \pm 11.06$ & 0.0006 \\
\hline RVEF (\%) & Median $(5 ; 95)$ & $64(55.15 ; 78.4)$ & $60(45.4 ; 80.8)$ & 0.081 \\
\hline T1-ratio & Median $(5 ; 95)$ & $4.8(2.0 ; 14.13)$ & $3.6(1.8 ; 10.6)$ & 0.076 \\
\hline T1 path., $n(\%)$ & Frequency & $24 / 31(77.4)$ & $8 / 30(26.7)$ & 0.0001 \\
\hline $\mathrm{PE}, n(\%)$ & Frequency & 7 (21.9) & $6(17.6)$ & 0.67 \\
\hline LGE, $n(\%)$ & Frequency & $8(23.5)$ & $3(9.1)$ & 0.11 \\
\hline
\end{tabular}

AHT, arterial hypertension; LVEDV, left ventricular end-diastolic volume; LVSV, left ventricular stroke volume; LVEF, left ventricular ejection fraction; RVEDV, right-ventricular enddiastolic volume; RVSV, right-ventricular stroke volume; PE, pericardial effusion; LGE, late gadolinium enhancement.

Significant $p$ values $<0.05$ are marked in bold. CMR indexes related to body surface areas (BSA), which was calculated by the Dubois and Dubois regression formula: $B S A=0.007184 \times$ weight $(\mathrm{kg})^{0.425} \times$ height $(\mathrm{cm})^{0.725}$.
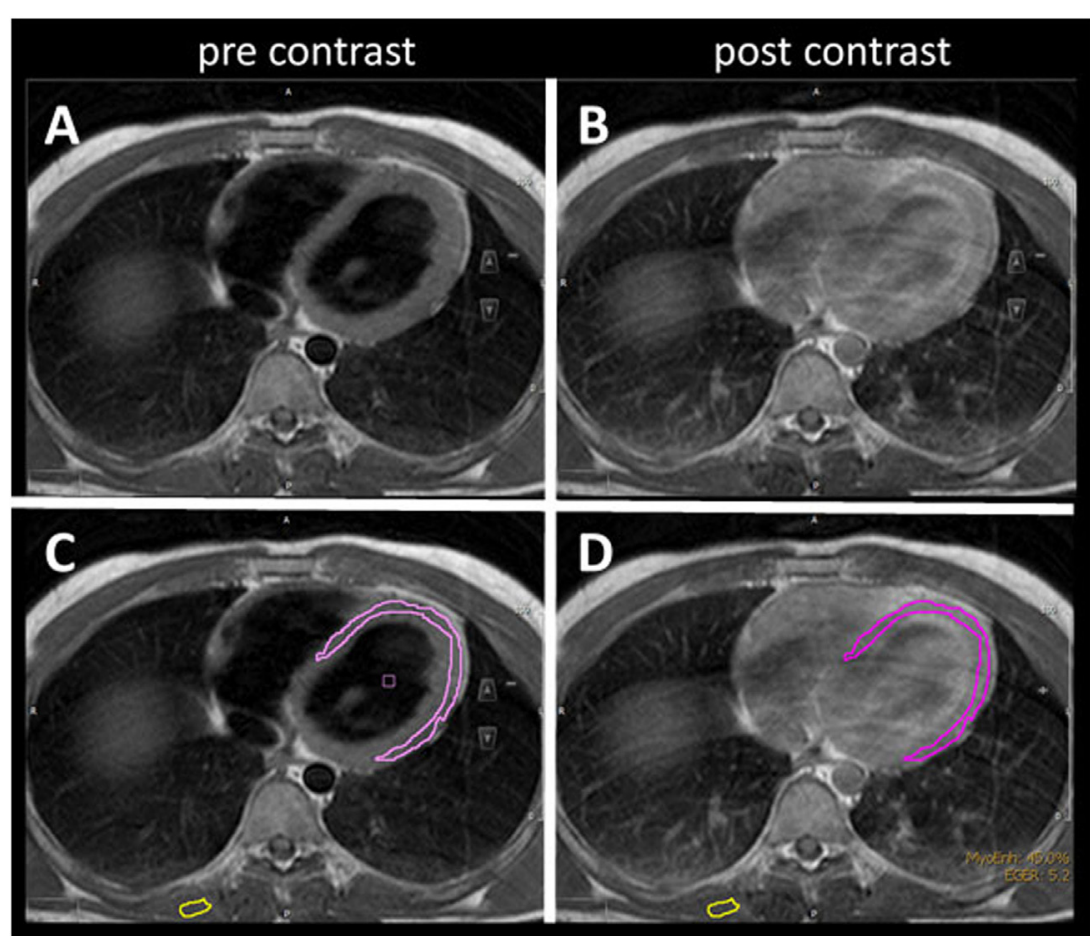

FIGURE 1 | T1 turbospinecho sequences in the transversal position before (A,C) and after (B,D) gadolinium administration. For quantification of early gadolinium enhancement, contours of the left ventricular myocardium (pink) and skeletal muscle (yellow) were manually delineated (C,D) in the pre- and post-contrast images.

patient, LGE was observed to be localized inferoseptally. These LGE patterns are not characteristic for an ischemic origin, but are commonly reported in inflammatory myocarditis or cardiac involvement in systemic diseases $(13,18)$.
A comparison of ALS patients with and without LGE and with or without increased T1 ratio did not show any statistical difference concerning heart function parameters and clinical severity (Table 4). 


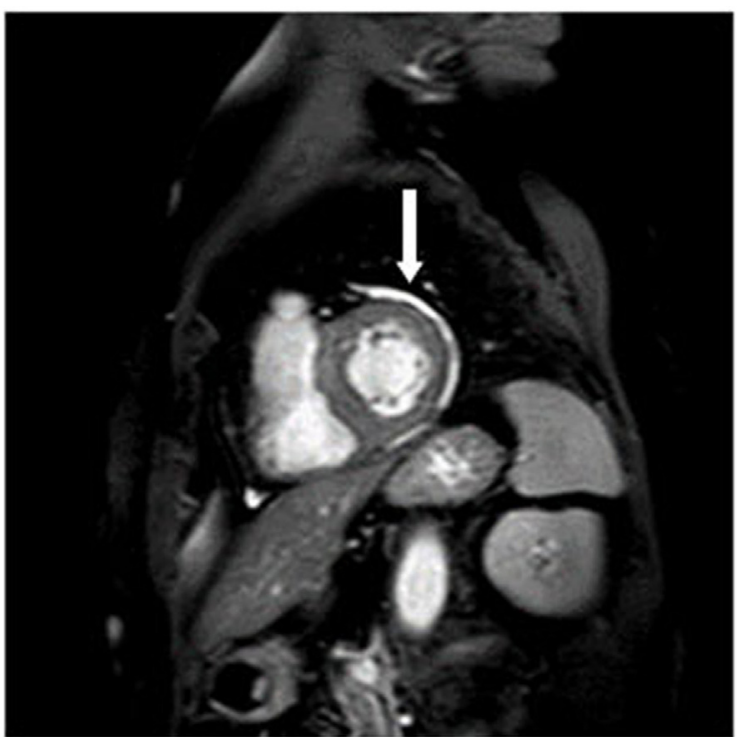

FIGURE 2 | Pericardial effusion (arrow) in short axis view.
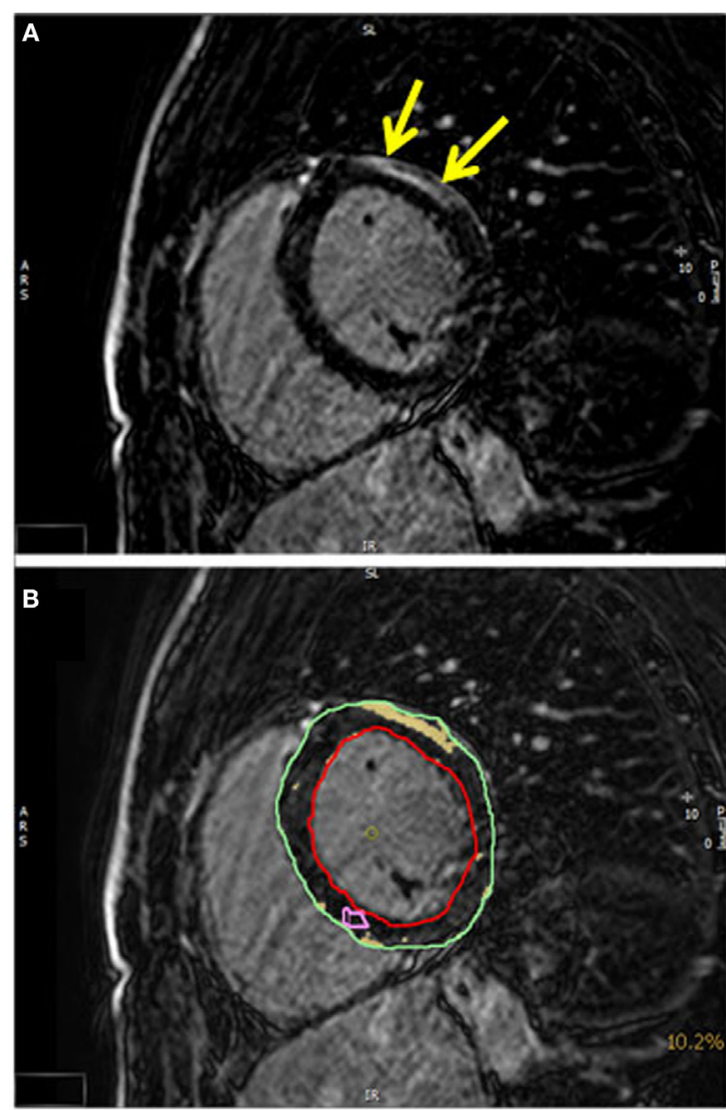

FIGURE 3 | (A) A T1-weighted inversion-recovery sequence in short axis view showing epicardial late enhancement in the anterolateral myocardia segments (yellow arrows). (B) The quantification of the late enhancement area (yellow) in relation to the myocardial mass (epicardial contour green and endocardial contour red).

\section{DISCUSSION}

As the rather frequent occurrence [10\% according to Ref. (3)] of cardiac deaths in ALS is not well understood (1), this study was performed in order to characterize myocardial tissue by CMR in ALS patients without any cardiac complaints. No significant abnormalities in the routine cardiac assessment with Holter monitoring and echocardiography could be found except slight valve insufficiencies in up to half of the patients. Recent studies have shown that CMR is an important diagnostic tool for detecting cardiac involvement in systemic diseases, such as cardiomyopathies and amyloidosis (22, 24-26). Abnormalities in CMR were frequent in ALS, in particular early gadolinium enhancement $(77 \%)$ as a parameter of enhanced extracellular volume, that is either capillary leakage or fibrosis. Pericardial effusions were detected in $22 \%$ and LGE in $23.5 \%$ as a marker of diffuse myocardial fibrosis. The latter abnormalities did not differ significantly from controls ( $17.6 \%$ effusions and 9.1\% LGE). None of the patients displayed any characteristics of cardiac ischemia that could account for the observed myocardial changes (ischemic pattern with a subendocardial and/or transmural enhancement).

In comparison with healthy controls, ALS patients showed significantly lower left and right ventricular volumes and ventricular mass. Since the heart scales with the size of the body and, therefore, with height and weight, we used the index of ventricular mass and volumes as a ratio to body surface area (BSA) for comparison with controls (Index $=$ mass/BSA or volume/BSA) (27).

Even after indexing these values to BSA, which may be lower in ALS patients, these differences remained. ALS hearts had lower myocardial mass than control hearts, and ejection volumes in the left and right heart were decreased in ALS patients. It is possible that reduced body weight or reduced physical activity may account for these abnormalities. There are studies implying that BMI is a strong predictor for heart mass (28), but our control group did not differ with regard to BMI. Reduced muscle mass or malnutrition, therefore, are not the cause for loss of myocardial mass in our cohort, as also shown by the statistically different indexes in Table 3.

The function and the size of the heart show a regression in healthy inactive persons even without any structural heart disease (29). Therefore, we assume that significantly reduced heart mass and ejection volumes are a consequence of more sedentary/ inactive behavior in ALS patients if compared to healthy adults.

At a higher age, even healthy persons show alterations in CMR as can be observed in our age-matched control cohort. Increased myocardial T1 values or LGE may be attributed to unrecognized cardiac events (myocarditis, infarction) and hypertension $(30,31)$. Since the frequency of diabetes differed significantly in cases and controls $(p=0.03)$, some of the reported abnormalities in ALS patients might be due to diabetic complications. With respect to CMR, a subclinical diastolic dysfunction but no significant fibrosis in LGE has been reported in diabetes (32). With respect to ALS, this finding has to be seen in the context of the association between diabetes (type 2) and ALS as previously reported $(33,34)$, but the data of our study cannot add substantially to this discussion. 
TABLE 4 | A comparison of amyotrophic lateral sclerosis patients with and without late gadolinium enhancement (LGE) or increased T1 enhancement concerning heart function parameters and clinical severity.

\begin{tabular}{|c|c|c|c|c|c|c|}
\hline & With LGE & Without LGE & $\begin{array}{l}\text { Unpaired } t \text {-test } \\
\text { LGE }\end{array}$ & With increased $\mathrm{T} 1$ ratio & $\begin{array}{c}\text { Without increased } \\
\text { T1 ratio }\end{array}$ & $\begin{array}{c}\text { Unpaired } t \text {-test } \\
\text { T1 ratio }\end{array}$ \\
\hline Cases, $N(\%)$ & $8(23.5)$ & $26(76.4)$ & 0.0063 & $24(77.4)$ & 7 (22.6) & $<0.0001$ \\
\hline Mass, g (mean $\pm \mathrm{SD})$ & $77 \pm 31$ & $81 \pm 25$ & 0.5366 & $77 \pm 33$ & $76 \pm 18$ & 0.9446 \\
\hline LVEF\% (mean \pm SD) & $63.9 \pm 5.4$ & $65.0 \pm 6.2$ & 0.5725 & $61.8 \pm 8.3$ & $64.1 \pm 5.6$ & 0.4910 \\
\hline RVEF\% (mean \pm SD) & $67.9 \pm 11.6$ & $63.5 \pm 6,2$ & 0.0676 & $59.3 \pm 10.7$ & $62.3 \pm 6.4$ & 0.4913 \\
\hline T1-ratio (Norm <4) (mean \pm SD) & $5.4 \pm 3.7$ & $5.8 \pm 3.7$ & 0.8907 & - & - & - \\
\hline LGE, $n(\%)$ & - & - & - & $3(13)$ & $1(14)$ & 0.9053 \\
\hline ALSFRS-R (points) (mean \pm SD) & $33.5 \pm 11.1$ & $32.0 \pm 7.8$ & 0.6676 & $31.6 \pm 8.6$ & $32.4 \pm 8.7$ & 0.8235 \\
\hline ALS duration (years) (mean $\pm S D$ ) & $1.4 \pm 0.7$ & $3.0 \pm 2.3$ & 0.0775 & $2.4 \pm 1.9$ & $3.6 \pm 2.9$ & 0.2136 \\
\hline
\end{tabular}

Significant $p$ values $<0.05$ are marked in bold.

With respect to the origin of the detected increased myocardial T1 values, typical patterns of myocardial infarction [subendocardial or transmural LGE pattern (35)] were not detected. In a disease with denervation as the main muscular pathology, early gadolinium enhancement is likely to be associated with denervation edema (36-38).

One explanation for denervation would be increased sympathetic activity induced by respiratory weakness and, therefore, pulmonary hypertension, but no signs of pulmonary hypertension could be detected in our patient cohort. Primary involvement of the autonomic cardiac nerves may be an explanation for postulated sympathetic hyperactivity. Several groups have detected evidence of sympathetic hyperactivity even at the time of the initial ALS diagnosis $(9,39,40)$. Additional studies reported primary sympathetic-impaired autonomic control in ALS patients by ECG abnormalities $(6,41)$. In a SOD1 mouse model of ALS, preganglionic sympathetic denervation was histologically confirmed (42). Tamsulosin hydrochloride as a selective alpha 1-adrenoceptor blocker was shown to be useful for suppressing central sympathetic hyperactivity but it was not tested for the long-term outcome of ALS patients (43).

Studies of pTDP-43 pathology in the brain and the associated neuronal loss have revealed involvement of amygdala and the hypothalamus as central sympathetic structures $(44,45)$.

Given that sympathetic hyperactivity can be associated with stress-induced cardiomyopathy and sudden cardiac death, this hypothesis may explain why sudden cardiac death is one of the main causes of death in ALS after respiratory insufficiency.

Laboratory parameters have shown increased level of CK, as expected in ALS patients, whereas troponin T as an acute cardiac marker was not increased. Heart failure leading to increased NT-pro BNP was rarely detected and could be attributed to (preexisting) structural defects. Therefore, CMR seems to be more sensitive for the detection of cardiac involvement in ALS than cardiac parameters in blood tests.

Limitations of this study are the inability to differentiate the gadolinium enhancement with regard to the underlying pathophysiology. Furthermore, our results probably underestimate cardiac changes due to relatively unaffected respiration of the ALS participants, since severely affected ALS patients could no longer lie flat in CMR.

In summary, functional cardiac involvement with a tendency toward lower ejection volumes in ALS hearts and an increase in early myocardial $\mathrm{T} 1$ contrast enhancement appears to be a common finding in ALS. The late enhancement distribution did not correspond to typical ischemic patterns with subendocardial involvement. Hence, the changes are unlikely due to cardiac ischemia and do not correlate with the clinical severity of ALS. We suggest that the most likely mechanism is a primary dysfunction of sympathetic heart regulation. If sympathetic hyperactivity is the cause for these alterations, therapeutic betaor alpha-blocking strategies should be considered and might be studied in future clinical trials.

\section{ETHICS STATEMENT}

This study was carried out in accordance with the recommendations of the Ethics Committee of the University of Ulm with written informed consent from all subjects. All subjects gave written informed consent in accordance with the Declaration of Helsinki. The protocol was approved by the Ethics Committee of the University of Ulm (protocols no. 11/10 and no. 05/11).

\section{AUTHOR CONTRIBUTIONS}

AR: acquisition of data, data analysis, writing of the manuscript draft, study supervision, and critical revision of manuscript. BS: acquisition of data, data analysis, interpretation of data, and writing of the manuscript draft. DB: acquisition of data, data analysis, writing of the manuscript draft, and critical revision of manuscript. JK: interpretation of data and critical revision of manuscript. WR: study concept and design, study supervision, and critical revision of manuscript. PB and AL: study concept and design, interpretation of data, study supervision, and critical revision of manuscript.

\section{ACKNOWLEDGMENTS}

We thank Kelly Del Tredici-Braak for the critical reading of the manuscript.

\section{FUNDING}

This work was partially supported by a grant from the German Society of Muscle Disease [Deutsche Gesellschaft für Muskelkranke e.V (DGM)] and by the German Research Council (Deutsche Forschungsgemeinschaft, DFG grant number LU 336/15-1) and the German Network of ALS (BMBF 01GM1103A). 


\section{REFERENCES}

1. Gil J, Funalot B, Verschueren A, Danel-Brunaud V, Camu W, Vandenberghe N, et al. Causes of death amongst French patients with amyotrophic lateral sclerosis: a prospective study. Eur J Neurol (2008) 15:1245-51. doi:10.1111/j.14681331.2008.02307.x

2. Spataro R, Lo Re M, Piccoli T, Piccoli F, La Bella V. Causes and place of death in Italian patients with amyotrophic lateral sclerosis. Acta Neurol Scand (2010) 122:217-23. doi:10.1111/j.1600-0404.2009.01290.x

3. Corcia P, Pradat P, Salachas F, Bruneteau G, le Forestier N, Seilhean D, et al. Causes of death in a post-mortem series of ALS patients. Amyotroph Lateral Scler (2008) 9:59-62. doi:10.1080/17482960701656940

4. Merico A, Cavinato M. Autonomic dysfunction in the early stage of ALS with bulbar involvement. Amyotroph Lateral Scler (2011) 12:363-7. doi:10.3109/ 17482968.2011.584628

5. Asai H, Hirano M, Udaka F, Shimada K, Oda M, Kubori T, et al. Sympathetic disturbances increase risk of sudden cardiac arrest in sporadic ALS. J Neurol Sci (2007) 254:78-83. doi:10.1016/j.jns.2007.01.007

6. Pavlovic S, Stevic Z, Milovanovic B, Milicic B, Rakocevic-Stojanovic V, Lavrnic D, et al. Impairment of cardiac autonomic control in patients with amyotrophic lateral sclerosis. Amyotroph Lateral Scler (2010) 11:272-6. doi:10.3109/17482960903390855

7. Murata Y, Harada T, Ishizaki F, Izumi Y, Nakamura S. An abnormal relationship between blood pressure and pulse rate in amyotrophic lateral sclerosis. Acta Neurol Scand (1996) 96:118-22. doi:10.1111/j.1600-0404.1997. tb00251.x

8. Gdynia HJ, Kurt A, Endruhn S, Ludolph AC, Sperfeld AD. Cardiomyopathy in motor neuron diseases. J Neurol Neurosurg Psychiatry (2006) 77:671-3. doi:10.1136/jnnp.2005.078600

9. Tanaka Y, Yamada M, Koumura A, Sakurai T, Hayashi Y, Kimura A, et al. Cardiac sympathetic function in the patients with amyotrophic lateral sclerosis: analysis using cardiac [123I] MIBG scintigraphy. J Neurol (2013) 260:2380-6. doi:10.1007/s00415-013-7005-0

10. Pinto S, Pinto A, De Carvalho M. Decreased heart rate variability predicts death in amyotrophic lateral sclerosis. Muscle Nerve (2012) 46:341-5. doi: $10.1002 /$ mus. 23313

11. Sancho J, Servera E, Diaz JL, Bañuls P, Marín J. Home tracheostomy mechanical ventilation in patients with amyotrophic lateral sclerosis. Thorax (2011) 66:948-52. doi:10.1136/thx.2011.160481

12. Shimizu T, Hayashi H, Kato S, Hayashi M, Tanabe H, Oda M. Circulatory collapse and sudden death in respirator-dependent amyotrophic lateral sclerosis. J Neurol Sci (1994) 124:45-55. doi:10.1016/0022-510X(94)90009-4

13. Marholdt H, Goedecke C, Wagner A, Meinhardt G, Athanasiadis A, Vogelsberg H, et al. Cardiovascular magnetic resonance assessment of human myocarditis: a comparison to histology and molecular pathology. Circulation (2004) 109:1250-8. doi:10.1161/01.CIR.0000118493.13323.81

14. Friedrich MG, Sechtem U, Schulz-Menger J, Holmvang G, Alakija P, Cooper LT, et al. Cardiovascular magnetic resonance in myocarditis: a JACC white paper. J Am Coll Cardiol (2009) 53:1475-87. doi:10.1016/j. jacc.2009.02.007

15. Ponfick M, Gdynia HJ, Kassubek J, Ludolph AC, Petscher K, Walcher T, et al. Cardiac involvement in juvenile overlap-myositis detected by cardiac magnetic resonance imaging. Int J Cardiol (2011) 152:e25-6. doi:10.1016/j.ijcard.2010.10.001

16. Rosenbohm A, Buckert D, Gerischer N, Walcher T, Kassubek J, Rottbauer W, et al. Early diagnosis of cardiac involvement in idiopathic inflammatory myopathy by cardiac magnetic resonance tomography. J Neurol (2015) 262:949-56. doi:10.1007/s00415-014-7623-1

17. Walcher T, Steinbach P, Spieß J, Kunze M, Gradinger R, Walcher D, et al. Detection of long-term progression of myocardial fibrosis in Duchenne muscular dystrophy in an affected family: a cardiovascular magnetic resonance study. Eur J Radiol (2011) 80:115-9. doi:10.1016/j.ejrad.2010.07.005

18. Yilmaz A, Gdynia HJ, Marholdt H, Sechtem U. Cardiovascular magnetic resonance reveals similar damage to heart of patients with Becker and limb-girdle muscular dystrophy but no cardiac symptoms. J Magn Reson Imaging (2009) 30:876-7. doi:10.1002/jmri.21905

19. Maisel A, Mueller C, Adams K Jr, Anker SD, Aspromonte N, Cleland JG, et al. State of the art: using natriuretic peptide levels in clinical practice. Eur J Heart Fail (2008) 10:824-39. doi:10.1016/j.ejheart.2008.07.014
20. Lang RM, Badano LP, Mor-Avi V, Afilalo J, Armstrong A, Ernande L, et al. Recommendations for cardiac chamber quantification by echocardiography in adults: an update from the American Society of Echocardiography and the European Association of Cardiovascular Imaging. Eur Heart J Cardiovasc Imaging (2015) 16(3):233-70. doi:10.1093/ehjci/jev014

21. Buckert D, Dewes P, Walcher T, Rottbauer W, Bernhardt P. Intermediate term prognostic value of reversible perfusion deficit diagnosed by adenosine perfusion cardiac magnetic resonance imaging - a prospective follow-up study in a consecutive patient population. JACC Cardiovasc Imaging (2013) 6:56-63. doi:10.1016/j.jcmg.2012.08.011

22. Gutberlet M, Spors B, Thoma T, Bertram H, Denecke T, Felix R, et al. Suspected chronic myocarditis at cardiac MR: diagnostic accuracy and association with immunohistologically detected inflammation and viral persistence. Radiology (2008) 246:401-9. doi:10.1148/radiol.2461062179

23. Laissy JP, Messin B, Varenne O, Iung B, Karila-Cohen D, Schouman-Claeys E, et al. MRI of acute myocarditis: a comprehensive approach based on various imaging sequences. Chest (2002) 122:1638-48. doi:10.1378/chest.122. 5.1638

24. Rudolph A, Abdel-Aty H, Bohl S, Boyé P, Zagrosek A, Dietz R, et al. Noninvasive detection of fibrosis applying contrast-enhanced cardiac magnetic resonance in different forms of left ventricular hypertrophy relation to remodeling. J Am Coll Cardiol (2009) 53:284-91. doi:10.1016/j. jacc.2008.08.064

25. von Knobelsdorff-Brenkenhoff F, Bublak A, El-Mahmoud S, Wassmuth R, Opitz C, Schulz-Menger J. Single-center survey of the application of cardiovascular magnetic resonance in clinical routine. Eur Heart J Cardiovasc Imaging (2013) 14:62-8. doi:10.1093/ehjci/jes125

26. Maceira AM, Prasad SK, Hawkins PN, Roughton M, Pennell DJ. Cardiovascular magnetic resonance and prognosis in cardiac amyloidosis. J Cardiovasc Magn Reson (2008) 10:54. doi:10.1186/1532-429X-10-54

27. Brumback LC, Kronmal R, Heckbert SR, Ni H, Hundley WG, Lima JA, et al. Body size adjustments for left ventricular mass by cardiovascular magnetic resonance and their impact on left ventricular hypertrophy classification. Int J Cardiovasc Imaging (2010) 26:459-68. doi:10.1007/s10554-0109584-5

28. Korre M, Porto LG, Farioli A, Yang J, Christiani DC, Christophi CA, et al. Effect of body mass index on left ventricular mass in career male firefighters. Am J Cardiol (2016) 118:1769-73. doi:10.1016/j.amjcard.2016. 08.058

29. Dickhuth HH, Röcker K, Mayer F, König D, Korsten-Reck U. [Endurance training and cardial adaptation (athlete's heart)]. Herz (2004) 29(4):373-80. doi:10.1007/s00059-004-2582-4

30. Themudo R, Johansson L, Ebeling-Barbier C, Lind L, Ahlström H, Bjerner T. The number of unrecognized myocardial infarction scars detected at DE-MRI increases during a 5-year follow-up. Eur Radiol (2017) 27:715-22. doi:10.1007/ s00330-016-4439-7

31. Andersen K, Hennersdorf M, Cohnen M, Blondin D, Modder U, Poll LW. Myocardial delayed contrast enhancement in patients with arterial hypertension: initial results of cardiac MRI. Eur J Radiol (2009) 71:75-81. doi:10.1016/j. ejrad.2008.03.009

32. Khan JN, Wilmot EG, Leggate M, Singh A, Yates T, Nimmo M, et al. Subclinical diastolic dysfunction in young adults with type 2 diabetes mellitus: a multiparametric contrast-enhanced cardiovascular magnetic resonance pilot study assessing potential mechanisms. Eur Heart J Cardiovasc Imaging (2014) 15(11):1263-9. doi:10.1093/ehjci/jeu121

33. Kioumourtzoglou MA, Rotem RS, Seals RM, Gredal O, Hansen J, Weisskopf MG. Diabetes mellitus, obesity, and diagnosis of amyotrophic lateral sclerosis: a population-based study. JAMA Neurol (2015) 72(8):905-11. doi:10.1001/jamaneurol.2015.0910

34. Logroscino G. Motor neuron disease: are diabetes and amyotrophic lateral sclerosis related? Nat Rev Neurol (2015) 11(9):488-90. doi:10.1038/nrneurol. 2015.145

35. Kim RJ, Fieno DS, Parrish TB, Harris K, Chen EL, Simonetti O, et al. Relationship of MRI delayed contrast enhancement to irreversible injury, infarct age, and contractile function. Circulation (1999) 9(100):1992-2002. doi:10.1161/01.CIR.100.19.1992

36. Bendszus M, Koltzenburg M. Visualization of denervated muscle by gadolinium-enhanced MRI. Neurology (2001) 57:1709. doi:10.1212/WNL.57. 9.1709 
37. Bendszus M, Koltzenburg M, Wessig C, Solymosi L. Sequential MR imaging of denervated muscle: experimental study. AJNR Am J Neuroradiol (2002) 23:1427. doi:10.1148/radiol.12111915

38. Goyault G, Bierry G, Holl N, Lhermitte B, Dietemann JL, Beregi JP, et al. Diffusion-weighted MRI, dynamic susceptibility contrast MRI and ultrasound perfusion quantification of denervated muscle in rabbits. Skeletal Radiol (2012) 41:33-40. doi:10.1007/s00256-011-1108-4

39. Shindo K, Watanabe H, Ohta E, Nagasaka T, Shiozawa Z, Takiyama Y. Sympathetic sudomotor neural function in amyotrophic lateral sclerosis. Amyotroph Lateral Scler (2011) 12:39-44. doi:10.3109/17482968.2010.508529

40. Karlsborg M, Andersen EB, Wiinberg N, Gredal O, Jørgensen L, Mehlsen J. Sympathetic dysfunction of central origin in patients with ALS. Eur J Neurol (2003) 10:229-34. doi:10.1046/j.1468-1331.2003.00578.x

41. Dalla Vecchia L, De Maria B, Marinou K, Sideri R, Lucini A, Porta A, et al. Cardiovascular neural regulation is impaired in amyotrophic lateral sclerosis patients. A study by spectral and complexity analysis of cardiovascular oscillations. Physiol Meas (2015) 36:659-70. doi:10.1088/0967-3334/ $36 / 4 / 659$

42. Kandinov B, Grigoriadis NC, Touloumi O, Drory VE, Offen D, Korczyn AD. Immunohistochemical analysis of sympathetic involvement in the SOD1G93A transgenic mouse model of amyotrophic lateral sclerosis. Amyotroph Lateral Scler Frontotemporal Degener (2013) 14:424-33. doi:10.3109/ 21678421.2013.780622
43. Ohno T, Shimizu T, Kato S, Hayashi H, Hirai S. Effect of tamsulosin hydrochloride on sympathetic hyperactivity in amyotrophic lateral sclerosis. Auton Neurosci (2001) 88:94-8. doi:10.1016/S1566-0702(01)00217-X

44. Brettschneider J, Del Tredici K, Toledo JB, Robinson JL, Irwin DJ, Grossman M, et al. Stages of pTDP-43 pathology in amyotrophic lateral sclerosis. Ann Neurol (2013) 74:20-38. doi:10.1002/ana.23937

45. Cykowski MD, Takei H, Schulz PE, Appel SH, Powell SZ. TDP-43 pathology in the basal forebrain and hypothalamus of patients with amyotrophic lateral sclerosis. Acta Neuropathol Commun (2014) 2:171. doi:10.1186/s40478014-0171-1

Conflict of Interest Statement: The authors declare that the research was conducted in the absence of any commercial or financial relationships that could be construed as a potential conflict of interest.

Copyright (C) 2017 Rosenbohm, Schmid, Buckert, Rottbauer, Kassubek, Ludolph and Bernhardt. This is an open-access article distributed under the terms of the Creative Commons Attribution License (CC BY). The use, distribution or reproduction in other forums is permitted, provided the original author(s) or licensor are credited and that the original publication in this journal is cited, in accordance with accepted academic practice. No use, distribution or reproduction is permitted which does not comply with these terms. 